\title{
The Role of Gender Stereotypes in Gubernatorial Campaign Coverage
}

\author{
Karen Bjerre \\ Department of Politics, Sewanee: The University of the South, Sewanee, TN \\ Student:bjerrkr0@sewanee.edu*,karen.bjerre@hotmail.com \\ Mentor:macrowde@sewanee.edu
}

\begin{abstract}
Through a content analysis of 1,152 articles covering 20 different gubernatorial races between 2004 and 2014, I examine how the presence of a woman candidate in a gubernatorial race affects media coverage of that campaign. This paper considers the prevalence of gender biases and stereotypes and examines whether print media outlets perpetuate these stereotypes or subvert them. Existing research suggests that voters favor traditionally masculine traits over traditionally feminine traits when evaluating candidates for public office. The difference in media coverage may therefore influence women's chances of getting elected, and thereby influence women's descriptive and substantive representation. I find that races with a woman candidate receive less issue coverage and more horse race coverage than races with two men running. Additionally, the types of adjectives used in campaign coverage differ depending on the gender of the candidate: women are more likely to be described as able to "change government," while men are more likely to be described as "experienced."
\end{abstract}

\section{KEYWORDS}

Media Coverage; Gender; Gubernatorial Campaigns; Women in Politics; Gender Stereotypes; Newspaper Coverage; American Politics

\section{INTRODUCTION}

At a campaign event about a month before the 2008 election, Beverly Perdue, a North Carolina gubernatorial candidate, shared her favorite introduction she had received with a crowd of supporters: "She's a good woman. But she fights like a man." 1 This statement exemplifies one of the many obstacles women face when running for elected office, in terms of gender stereotypes and social role congruity. The fact that being a "fighter" is inherently associated with masculinity forces women in political campaigns to pursue a delicate balance between being masculine enough for the job while maintaining enough femininity to be likeable. ${ }^{2}$ These gendered expectations are embedded in today's society and might explain why Claire McCaskill agreed to be interviewed in her kitchen, while running for Governor of Missouri. Being interviewed in her home emphasizes traditionally feminine characteristics, which could help balance out more assertive behavior in other contexts.

Even though women continue to be elected to political offices, the U.S. is still a long way from equal representation by gender. No level of office in the United States currently has more than 26 percent women representatives, and only six women are currently serving as governors of their states. ${ }^{3}$ For the time period examined in this paper $(2004-2014)$, eight of the ten races where a woman was competitive in the gubernatorial election, took place in states that had never had a woman governor. ${ }^{4}$ This underrepresentation is significant because it can affect substantive representation, future descriptive representation, and overall levels of participation for women. These patterns reinforce themselves in a cycle in which women have lower levels of political ambition than men, ${ }^{5}$ they are more politically engaged when a woman is competitive in a given electoral contest, ${ }^{6}$ and elected officials, who are women, are more likely to work on so called 'women's issues. ${ }^{7}$ Therefore, the descriptive representation of women at all levels of U.S. politics is important because it holds the potential to increase political ambition and efficacy among women and girls. ${ }^{6}$

In this paper, I examine how gender cues and stereotypes influence the media. Specifically, I test whether or not significant differences in news coverage exist between men and women candidates for governor. I choose to focus on gubernatorial contests because I am interested in the gender dynamics in elections for executive positions, and the gubernatorial level is the highest in which several women have both run and won. I find that the types of coverage each candidate receives differ by gender, especially when it comes to whether the coverage focuses on issue or horse race stories. Women candidates, as well as men running against women, are less likely than men running against men to receive substantive coverage of their issue positions.

I begin by establishing why it matters if women hold elected office. In that context, I address distinctions in issue competency evaluations, differences in legislative agendas developed by men and women, and the broader societal effects of electing women to office. To explain my focus on gubernatorial candidates, I then examine how theories of gender congruency and stereotypes affect women candidates and their constituents differently depending on the level of office in question. Finally, I look at how 
gender influences political campaigns in U.S. politics through the lens of media coverage, and how media coverage influences the broader public. This examination of existing scholarship lays the foundation for my hypotheses regarding how candidate gender affects media coverage.

\section{LITERATURE REVIEW}

Women as Elected Officials

I am evaluating how media coverage differs for men and women candidates to determine whether or not the media contributes to women's political underrepresentation. Some scholars have found effects of candidate gender on the issues covered in political campaigns to be negligible, and significantly smaller than party effects, ${ }^{8}$ while several other studies of politicians' legislative behavior indicate that the descriptive representation of women leads to more substantive representation of women. Specifically, when it comes to substantive representation, several scholars have found evidence that the legislative agendas for women differ from those of men, especially when it comes to working with "women's issues."7, 9 These authors find that women senators are more likely to focus on issues such as education and health care in their legislative careers, while their colleagues prioritize issues surrounding the economy and national security. The findings suggest that gender might be a causal factor in the differences that develop between men and women in politics. However, the studies do not reveal why women pursue different legislative goals than men. Additionally, as these studies have focused on legislative positions at different levels, it is unclear how their findings translate to executive positions. Regardless of why these differences emerge, the descriptive representation of women appears to further the substantive representation of so called "women's issues."

These differences in legislative agendas align with classifications made by several researchers, to identify sets of policies as either masculine or feminine in nature. For example, Dolan identifies abortion, child care, education, and health care as traditionally feminine issues, while she categorizes the economy, national security, the deficit, immigration, and crime as masculine issues. ${ }^{10}$ These classifications are consistent with Fridkin and Kenney's ${ }^{9}$ framework for their analysis of senators' communications.

While a legislator might decide to work on specific issues on which he or she is particularly qualified, ${ }^{11}$ such decisions might also be made based on other factors such as perceived competency based on stereotypes, which can harm the prospects of women running for office. Several studies have found that issue competency evaluations from constituents vary both by partisanship and gender. ${ }^{12,13}$ This means that women are perceived as more competent at handling care issues, such as health care and education, while men seem to be particularly advantaged when it comes to perceptions of competence in the areas of national security. These differences function to create a sense of issue ownership based on gender that parallels the areas of issue ownership claimed by the Republican and Democratic party. ${ }^{14}$ These differences in competency evaluations seem likely to influence campaign and legislative activities alike, and therefore inform my expectations of how stereotypes might manifest themselves in campaign coverage, regarding both gender and partisanship.

Based on the distinctions of issue competencies, Kahn asserts that state offices might be more congruent with feminine stereotypes based on the increased focus on education and other social policies that are controlled at the state level. ${ }^{15}$ Ultimately, the differences in issue competency evaluations for men and women can be a hinderance for women running for office, considering Banwart's ${ }^{12}$ finding that stereotypically feminine issues are considered less important than issues such as the economy and national security. This leaves women politicians with a dilemma, since the issues they are considered the most competent at handling are also those generally rated as less important than the issues that favor their colleagues that are men. In the case of women running in gubernatorial races, these two approaches to stereotypes' role in politics point to different outcomes for women candidates. The first step must therefore be to establish whether these feminine stereotypes and issues are more prevalent in the women's gubernatorial campaigns.

This study seeks to enhance the knowledge of how gender stereotypes interact with media coverage, as recent research suggests that the dynamics of gender stereotypes on the campaign trail are changing. ${ }^{8,16}$ While research from the 1990 s and early 2000 s clearly indicated that gender stereotypes played a role in shaping how women candidates across different levels of office were perceived, ${ }^{17,18}$ more recent studies indicate that the prevalence of gender stereotypes, and their influence on women's electoral fortunes is declining. ${ }^{8,16}$ Additionally, Dolan and Lynch find that feminine stereotypes affect women candidates differently, depending on the candidate's partisanship. ${ }^{16}$ This study focuses on gubernatorial campaigns between 2004 and 2014 to explore the changing media landscape for women running for executive positions. This time frame is especially interesting, as it spans the apparent shift in how stereotypes affect the evaluations of women candidates, outlined above..$^{8,16-18}$

Gender congruity

There are reasons to expect gender stereotypes to both help and hinder women gubernatorial candidates, depending on which stereotypes are primed by the media. The traditional lack of foreign policy or national security concerns associated with a governor may help women candidates overcome the barrier of traditional gender roles, which is one example of how traditional 
gender stereotypes sometimes counteract each other at higher levels of office. ${ }^{17}$ Eagly's and Karau's finding that "the activation of beliefs about women and men by gender-related cues... influences people to perceive women as communal but not very agentic and men as agentic but not very communal" (575), ${ }^{19}$ should help women candidates in the case of gubernatorial races, because many communal policy areas such as education child care are controlled at the state level. ${ }^{15}$ However, they also find that people are evaluated less positively when their social role is incongruent with their stereotype. This second aspect of their findings could negatively affect the evaluations of women running for office, especially offices with executive powers such as governors, which have traditionally been perceived as masculine in nature. ${ }^{18}$ Delineating the effects of stereotypes and gender role congruity is therefore complicated by the interactions between the two.

The case highlighted in the introduction exemplifies how women candidates might try to navigate this gendered terrain. Beverly Perdue's introduction: "She's a good woman. But she fights like a man"1 demonstrates a balance between being feminine enough to get the benefits of positive feminine stereotypes, while also projecting strength and assertiveness. Insofar as these frames translate into the media coverage, the candidate manages to combine the positive aspects of both masculine and feminine traits.

\section{Media effects}

Whether or not the media is receptive to the candidates' use or rejection of stereotypes matters to campaigns, as studies have shown that editorial slant and media coverage of campaigns influence the decisions of voters exposed to the coverage. ${ }^{20,21}$ Specifically, voters base their own evaluative parameters for candidates on the kinds of issues and traits local newspapers have been priming. ${ }^{20}$ Campaign coverage by newspapers influences issue salience, which in turn influences voters. ${ }^{21}$ This establishes an important baseline, since a study of newspaper coverage carries little weight if any effects found are unlikely to influence the public. However, based on these studies, I expect that any gender-based differences I identify in news coverage affect the parameters voters use to evaluate candidates.

Existing research on gender differences in campaign coverage of candidates is mixed in its findings. In their study of newspaper ideology and coverage of woman candidates, Shor et al.22 find that newspapers from across the ideological spectrum cover women candidates significantly less than men running for office. Contrasting these findings, Hayes and Lawless ${ }^{8}$ find that women congressional candidates do not face media coverage that differs from that of their men counterparts. Instead, they argue that partisanship is the driving force behind media coverage and voter behavior alike. An important aspect of this argument is that the novelty seems to have worn off for women congressional candidates, leading reporters to cover them similarly to men candidates. However, at the gubernatorial level, women candidates may still be a novelty (As of 2018, 39 women governors have served in 28 states), ${ }^{4}$ and the decreased novelty of women in legislative positions does not necessarily translate to executive positions, which makes gubernatorial races particularly interesting to study. Finally, as media attention increases with the level of office, the likelihood that gendered media coverage will affect voters can similarly increase.

Whether or not the media covers women candidates differently from their men counterparts is important because Fox and Lawless ${ }^{5}$ find that, in the development of political ambition, women's fear of facing biased media coverage presents a significant deterrent in the decision to run for elected office. This hesitation suggests that biased media coverage might be a contributing factor to the significant gender gap in descriptive representation. The differential media coverage based on gender does not influence candidate ambition alone. These differences matter as the media's coverage of women's campaigns for office exert a lot of power over how these women are perceived by the general public, especially if the news media perpetuates gendered stereotypes. ${ }^{15,18,23-25}$ These studies about gender cues in politics indicate that women candidates might not be able to escape gender stereotypes, even in the minds of the well-informed voter, since media priming has been shown to influence the criteria voters use to evaluate candidates. ${ }^{26}$ Differential coverage thereby becomes a problem insofar as the news media reinforces gender stereotypes, since this might make the negative effects of social role incongruity for women candidates even more severe. In other words, gendered media coverage may make it harder for women to win elected offices, depending on the stereotypes in question.

Even when women politicians seek to counter gender stereotypes about issue competency, the media is not necessarily responsive. In their comparison of candidates' communications and media coverage, Fridkin and Kenney find that, while women politicians often try to focus on masculine qualities on their own websites and in other candidate communications, these efforts are not reflected in the media coverage they receive. ${ }^{9}$ Instead, local newspapers seem to reinforce gender stereotypes in their coverage. This demonstrates that, while media coverage-at least in newspapers-rarely makes explicitly sexist comments, the gender-specific expectations of women candidates nevertheless influence how they are described and perceived.

Overall, the literature suggests that gender stereotypes not only affect candidates' and elected officials' behavior, they have also been known to influence the types of news coverage political candidates and issues receive, and how people evaluate peers and leaders. ${ }^{19}$ Media coverage, as the link between politicians and constituents, holds the potential to counteract stereotypes, but has not yet consistently done so, though recent research suggests that this tide is turning. ${ }^{8}, 16$ Studying the extent of biased media 
coverage therefore provides us with an idea of how perceptions of politics and women candidates might be changed. Ultimately, while this project seeks to identify whether gender differences in newspaper coverage exists in gubernatorial campaigns, demonstrating the consequences of any such differences is beyond the scope of this study.

\section{Hypotheses}

I focus this study on gubernatorial races taking place between 2004 and 2014, as these races will generally both be high profile campaigns and be simultaneously incongruent with feminine stereotypes related to executive positions ${ }^{17,18}$ and congruent with stereotypes regarding feminine policy areas. ${ }^{15}$ These conditions are important to my research because they help ensure a wide enough set of data to allow me to draw meaningful conclusions about media coverage of women candidates, and because the consequences of media biases based on gender stereotypes seem especially complex at this level. Additionally, this time period covers the change in the literature outlined above, wherein gender stereotypes have moved from a central position in women's campaigns, ${ }^{17}, 18$ to being far less prominent. ${ }^{16,21}$ As the more recent studies that find declining use of gender stereotypes all use data collected towards the end of my own dataset, ${ }^{16,21} \mathrm{I}$ primarily base my hypotheses on the earlier literature.

I examine differential media coverage through the lens of how gender trait descriptions and issue competency evaluations are used to describe candidates for elective office. ${ }^{12,13}$ These studies align with the distinctions made earlier about feminine versus masculine policy issues, where women are seen as more competent at dealing with the communal issues of health care and education, while men are seen as more competent at handling national security and the economy. Based on these considerations, I hypothesize the following:

Hypothesis 1: Men and women candidates will be more likely to receive newspaper coverage on issues that are congruent with their respective gender stereotypes.

Hypothesis 2: Men and women candidates will be more likely to be described using adjectives that are congruent with their respective gender stereotypes.

For gendered adjectives, I use Dolan's ${ }^{23}$ distinctions, which build on the work of Huddy and Terkildsen, ${ }^{13}$ between masculine traits, including being "decisive," "experienced," "intelligent," and a "strong leader" and feminine traits such as being "able to change government," “compassionate," "consensus building," and "honest." Similarly, I separate policy issues as well as gendered traits according to Dolan's ${ }^{23}$ work on gender stereotypes in politics. This research identifies abortion, child care, education, and health care as feminine issues, while the economy, national security, the deficit, immigration, and crime are categorized as masculine issues. These distinctions between masculine and feminine policy areas align with Eagly and Karau's ${ }^{19}$ framework on communal and agentic social roles. While theses stereotypes are rooted in binary ideas about gender, they represent views that are still broadly held by members of American society, ${ }^{19,27}$ and thus may have influence over the journalists who must produce coverage appealing to American media consumers. ${ }^{28}$ It is worth noting that these distinctions largely overlap with competency evaluations of the Democratic and Republican parties. ${ }^{14}$ For this reason, I control for the partisan affiliation of the candidates throughout my analysis.

In addition to news coverage that relies on gender stereotypes, women candidates are traditionally disadvantaged when it comes to receiving coverage of policy issues. Rather than issue coverage, some studies suggest they are more likely to be covered in terms of public opinion and campaign strategy. These horse race stories compose a large part of the coverage of political campaigns at all levels, but the problem seems to be especially salient for women candidates, ${ }^{9}$ which might be explained by the continued novelty of women candidates, especially at higher levels of office ${ }^{3}$ In their study of women candidates and the role of the women voters, Goldenberg and $\mathrm{Kahn}^{29}$ found that women candidates not only get less coverage, but the coverage they do receive is more likely to focus on horse race stories than that of their men colleagues, meaning that news stories tend to focus more on a candidate's viability, endorsements, or campaign funds than his or her policy positions. Based on these findings, I hypothesize that:

Hypothesis 3: Horse race coverage will constitute a larger proportion of women candidates' news coverage than the corresponding proportion for men candidates. It follows that issue coverage will constitute a smaller proportion of women candidates' news coverage than the corresponding proportion for men candidates.

A lack of issue coverage poses a challenge to the women candidates, as issue-oriented news coverage can help voters formulate criteria on which to judge candidates. ${ }^{20,21}$ Less issue coverage might therefore lead voters to be more reliant on gender cues and stereotypes in their voting decision than might otherwise be the case or cause them to think women candidates lack issue competency. 
Finally, I am interested in whether differential coverage applies only to women candidates, or if the effects of gender stereotypes influence the media's coverage of the men running against them as well. Addressing how men running against women are covered differently than men running against other men might indicate the direction in which campaign coverage is headed, as women candidates for executive offices become more common. While I am not aware of any research that addresses how campaign coverage differs for men running against women as opposed to coverage of campaigns with two men running against each other, I do expect these men to be covered differently, as the presence of a women candidate makes gender more salient to reporters. This expectation leads me to hypothesize that:

Hypothesis 4: Mixed-gender* campaigns will be covered differently on each of the distinctions outlined in the previous hypotheses than campaigns in which two men are running against each other.

Ideally, I would also examine how coverage differs for women depending on the gender of their opponent; however, there is not enough available data for competitive gubernatorial races with two women running against each other.

\section{METHODOLOGY}

In order to test my hypotheses, I conducted a content analysis of news articles covering 20 different competitive, open seat gubernatorial campaigns. Print media, specifically newspapers, has been shown to be more effective at transmitting political information to consumers than TV and radio news, ${ }^{30}$ and has been shown to influence the criteria voters use to judge political candidates. ${ }^{26}$ Newspapers are expected to have a relatively higher standard of unbiased writing than TV sources, ${ }^{30,31}$ and are also more likely to frame their campaign coverage as issue stories. ${ }^{26}$ Therefore, if I find evidence of gender differences in media coverage among newspaper stories, this is likely a conservative estimate of bias compared to what is present in online or television news sources. I focus on open seat races to address Arnold's conclusion that newspapers cover incumbents and challengers differently. ${ }^{33}$ For the purposes of this project, I define competitive races by the standard established by Atkeson as contests with "a $10 \%$ or lower margin of victory between the winner and the runner up" (p. 1046). ${ }^{6}$

I establish a matched pair design by pairing competitive races with at least one woman candidate (one contest, New Mexico 2010 , had to women candidates) with similar races with only men candidates. The list of the 20 pairs (40 candidates total) I study can be found in Table 1 of the appendix. When pairing races with similar contests, I considered geographical region, year, and demographic similarity on factors such as state partisanship and ethnic composition. The matched pair design helps account for underlying factors that might otherwise confound my findings, as the pairs serve to essentially control for differences based on demographic or temporal effects. Pairs are made within the same presidential election cycle to ensure similarity in the national political context.

To find articles about my selected candidates, I searched Lexis Nexis, a database containing content from more than 3,000 newspapers. In my search on Lexis Nexis, I looked for articles that mentioned the candidate's name three months prior to the election. Using a random number generator, I selected 30 articles per candidate, except in cases where fewer than 30 articles were available (Brian Schweitzer, MT 2004; Bob Brown, MT 2004; Dina Titus, NV 2006), for a total of 1,152 observations. I coded each article on an array of variables including mentions of a candidate's appearance, whether the story was horse race coverage or issue focused, the general tone of coverage (positive, neutral, or negative), and mentions of specific issues (full list in the appendix). The policy issues for which I coded were classified as either masculine or feminine. The measure of inter-coder reliability is outlined in the appendix along with the codebook.

To define masculine and feminine policies, I followed the model used by Dolan in chapter three "When Does Gender Matter?"10 Her list of feminine policies includes abortion, child care, education, and health care, while her list of masculine policies includes crime, the deficit, the economy, immigration, and national security. This model is similar to those used by other scholars. ${ }^{3}$ Similarly, I used Dolan's distinctions between masculine traits (decisive, experienced, intelligent, strong leader) and feminine traits (able to change government, compassionate, consensus building, honest). ${ }^{10}$

I created scales for policy mentions by combining all the masculine policies into one dependent variable and all the feminine policies into another dependent variable. These scaled variables add up the number of mentions of each policy issue, with possible values for each article ranging from zero (no mentions of any of the policies) to five (mentions all the individual policies). I used the same structure in setting up scales for masculine and feminine trait mentions. Finally, I established another dependent variable

\footnotetext{
${ }^{*}$ While it is important to note that gender is not a simple binary identity, in this project I am constrained to studying the candidates that have sought gubernatorial office in the United States so far, all of whom have presented themselves in ways consistent with a male or female gender identity. Therefore, I have developed hypotheses and analyses organized around this gender identity comparison, and I look forward to future work which can investigate media portrayals of candidates who identify differently regarding gender in the future.
} 
by coding every article as focused on either issue- or horse race coverage. I classified stories as issue oriented if their focus was on specific policy positions, or challenges facing the state, while stories were classified as horse race coverage if they focused on polls, campaign events, fundraising efforts or endorsements.

In order to assess the overarching frames used in the campaign coverage of women candidates, I recorded all categories of data based on mentions of relevant words and phrases regardless of whether the word or trait was ascribed to the candidate in question or a related person in the article. I base this decision on the idea that being compared to a woman candidate might lead men candidates to be measured by traits that I categorize as 'feminine,' such as honesty and consensus building. Likewise, I record instances where a candidate is described as lacking in one of these qualities in the same way because these instances still convey the importance of said trait to the evaluation of the candidate. In addition to evaluating overarching frames of the campaigns, this decision also helped reduce discrepancies between coders, thereby strengthening the inter-coder reliability.

Based on several studies that have found that issue competency evaluations differ by both gender and partisanship, ${ }^{12-14}$ and that issue competency, especially concerning national security, is evaluated differently for Republican and Democratic women, ${ }^{27} \mathrm{I}$ included a control variable for party ID throughout my analysis. I also controlled for presidential election cycle, coded as either pre- or post-2008, to account for the potentially confounding factor of presidential agenda setting. Specifically, health care, an issue classified as feminine, received prominent coverage in the post-2008 period based on presidential politics rather than gender. Similarly, the economic downturn in 2008 , and subsequent efforts to stimulate the economy, may have led to an increase in coverage of economic issues post-2008 for reasons unrelated to gubernatorial candidate gender. While this dummy-variable is unlikely to capture all the effects, it is captures the major trends related to presidential politics.

\section{DATA AND RESULTS}

The first two columns of Table 1 show the results of a regression analysis with each of the policy scales as the dependent variable, containing the policy issues discussed in the methodology section, and includes controls for presidential cycle (pre-2008) and partisanship. The coefficient for the gender variable for the feminine policy scale is negative and marginally statistically significant $(\mathrm{p}<0.1)$, which indicates that women candidates are less likely than their men counterparts to receive coverage on issues considered traditionally feminine. This means that my first hypothesis is not supported for women candidates; rather than receiving more coverage on feminine issues, women running for office receive significantly less coverage on these issues than their men counterparts. For the other dependent variable, the masculine policy scale, the gender coefficient does not reach statistical significance. The analysis of the combined policy scales therefore does not support my first hypothesis.

\begin{tabular}{|c|c|c|c|c|c|}
\hline & $\begin{array}{c}\text { Feminine Policy } \\
\text { Scale }\end{array}$ & $\begin{array}{c}\text { Masculine Policy } \\
\text { Scale }\end{array}$ & $\begin{array}{c}\text { Feminine Trait } \\
\text { Scale }\end{array}$ & $\begin{array}{c}\text { Masculine Trait } \\
\text { Scale }\end{array}$ & Issue Coverage \\
\hline Woman & $-0.0827 \dagger$ & -0.0214 & $0.0642^{* *}$ & $-0.0392^{*}$ & -0.0531 \\
& $(0.050)$ & $(0.455)$ & $(0.021)$ & $(0.019)$ & $(0.032)$ \\
\hline Democrat & -0.0005 & -0.0281 & -0.0224 & -0.0164 & 0.04670 \\
& $(0.045)$ & $(0.042)$ & $(0.015)$ & $(0.020)$ & $(0.029)$ \\
\hline Pre-2008 & 0.0165 & -0.0608 & 0.0215 & -0.0059 & 0.01039 \\
& $(0.045)$ & $(0.041)$ & $(0.014)$ & $(0.020)$ & $(0.029)$ \\
\hline Constant & $0.4780 * *$ & $0.4694 * *$ & $0.0317 * *$ & $0.1192 * *$ & $0.29401 * *$ \\
& $(0.038)$ & $(0.035)$ & $(0.010)$ & $(0.019)$ & $(0.024)$ \\
\hline
\end{tabular}

Table 1. Policy and Trait Coverage of Women Candidates-Table shows OLS regression coefficients with standard errors in parentheses. ${ }_{\mathrm{p}} \mathrm{p}<0.1 \quad *_{\mathrm{p}}<0.05 \quad * *_{\mathrm{p}}<0.01$

When evaluating coverage of the individual issues contained in the policy scales, it becomes clear that gender does not influence coverage in the same way for each issue. The coefficients and confidence intervals for the Woman independent variable in individual regressions with media coverage of each policy area as a dependent variable are graphed in Figure 1. The gender variable fails to reach statistical significance for several of the policy issues. Education, crime, the economy, the deficit, and immigration are all issues where the gender variable is not statistically significant. However, counter to my hypothesis, the gender coefficient for coverage of both health care and abortion is negative and statistically significant $(p<0.05)$. This indicates that men candidates are more likely than women candidates to receive coverage of these issues otherwise classified as feminine. On the other hand, the child care and security variables both act as expected, with a gender coefficient that is positive and statistically 
significant $(p<0.05)$ for child care, and a negative and statistically significant coefficient for security ( $<<0.05)$. So, while these two variables support my initial hypothesis, the results from the other policy issues are inconsistent with my expectations.

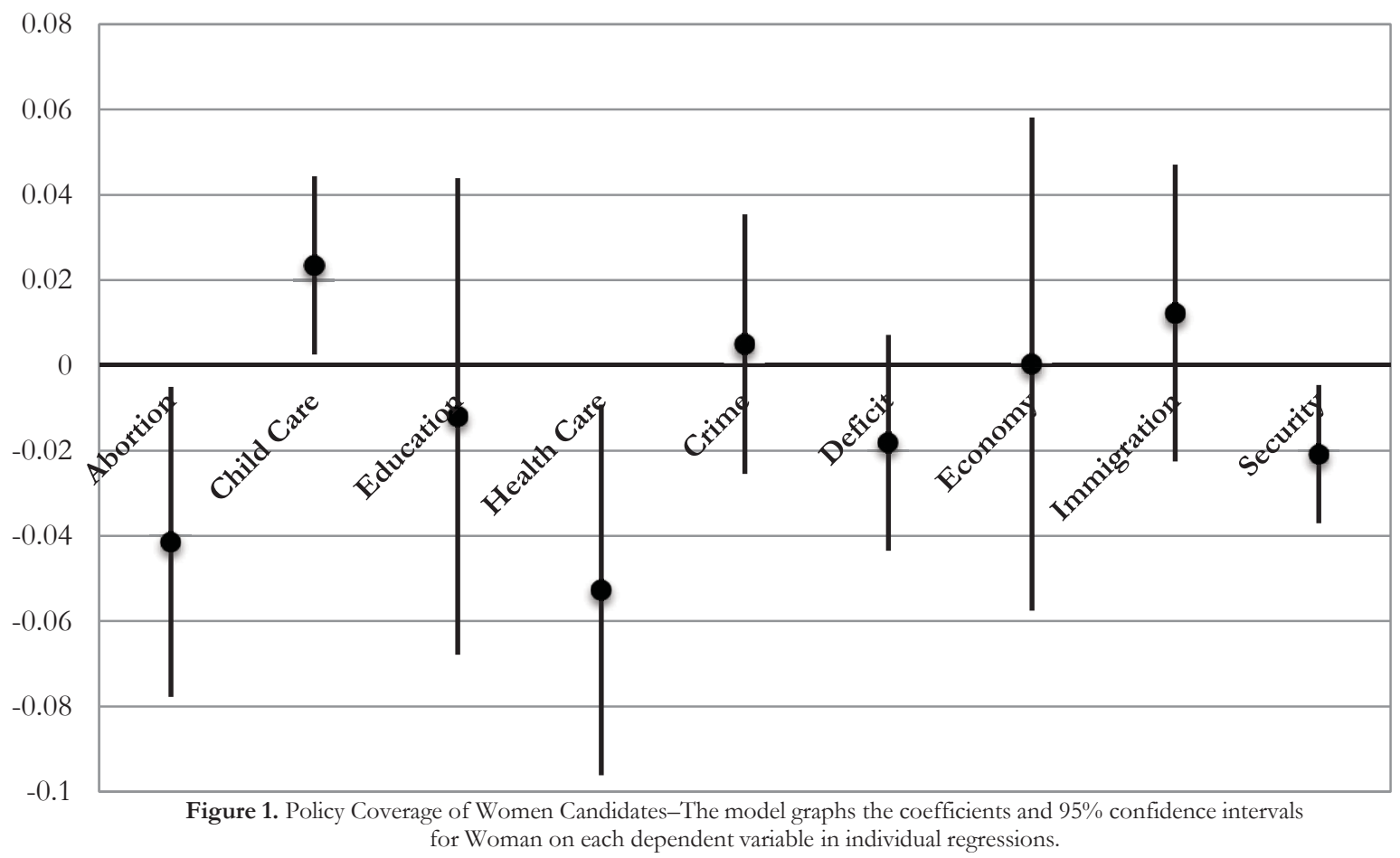

For my second hypothesis, that candidates will be more likely to be described using adjectives that are congruent with gender stereotypes, I develop a similar system. I created masculine and feminine trait scales, with possible values between zero (no mentions of any of the traits) to five (mentions all the individual traits), based on Dolan's ${ }^{10}$ framework. The third and fourth columns of Table 1 show the results of regression analyses on masculine and feminine trait scales, with a measure of candidate gender as the key independent variable and controls added for temporal effects and party ID. The results are consistent with my hypothesis, with a positive and statistically significant $(\mathrm{p}<0.05)$ coefficient for gender on the feminine trait scale, and a negative and statistically significant $(\mathrm{p}<0.05)$ coefficient for gender on the masculine trait scale. Together, these results support my second hypothesis; they confirm that women candidates are overall more likely to be described using traditionally feminine adjectives, while men candidates are more likely to be described using traditionally masculine adjectives.

Figure 2 shows the coefficients and confidence intervals of individual regressions with the media coverage of individual traits as the dependent variables and with gender as the key independent variable. The graph shows that being described as being able to 'change government' is individually significant $(\mathrm{p}<0.05)$ with a positive coefficient that supports my hypothesis. While not immediately obvious, since the figure graphs a $95 \%$ confidence interval, the honesty and experience variables both reach statistical significance with the gender variable at $\mathrm{p}<0.1$ and $\mathrm{p}<0.06$ respectively. Both of these dependent variables also act in the expected direction, which further supports my hypothesis. While several of the coefficients for Woman in these individual models do not reach statistical significance, the results suggest that women candidates are more likely to be described as honest and able to 'change government,' while men candidates are more likely to be described as experienced. Finally, the "decisive" trait previously identified as masculine was not used as a descriptor in any of the articles in the dataset and was therefore dropped from the analysis. 


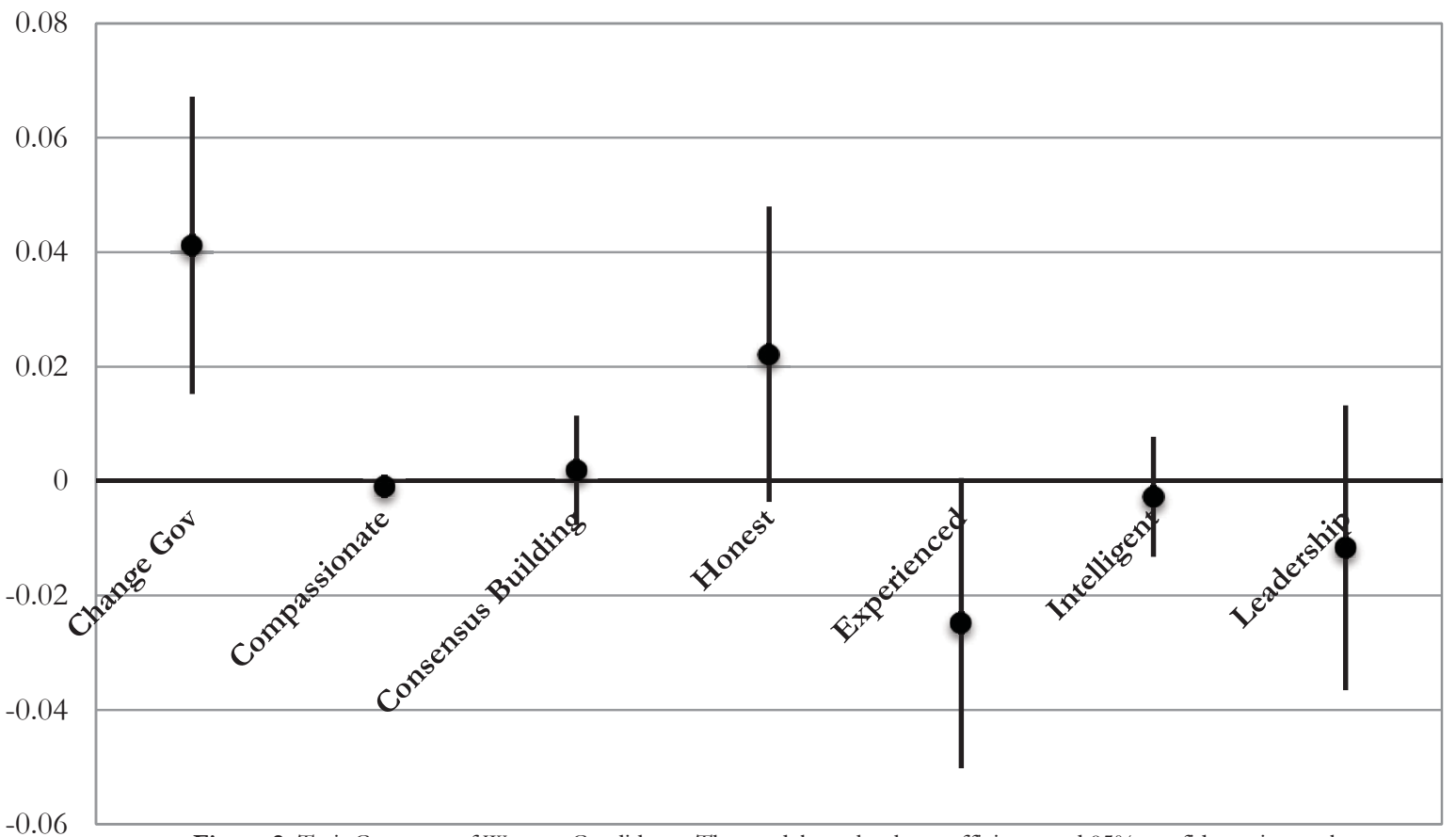

Figure 2. Trait Coverage of Women Candidates-The model graphs the coefficients and 95\% confidence intervals for Woman on each dependent variable in individual regressions.

For my third hypothesis regarding issue coverage versus horse race stories, I start by examining the percentage of horse race stories by gender. I find that about six percentage points more of the coverage of women candidates is classified as horse race stories than the corresponding coverage level for men candidates. However, as seen in the fifth column of Table 1, the regression analysis shows that these results fall just short of statistical significance $(p=0.101)$. However, as the first column of Table 2 shows, a similar analysis of mixed-gender races indicates that these receive significantly less issue coverage than races in which two men are running against each other. While my hypothesis is not directly supported, I do find evidence that the presence of a woman candidate leads to a lower level of issue coverage for both her and her opponent. This trend might be explained by a focus on the gender frame rather than a more traditional frame. For example, stories about potentially electing the state's first woman governor were prevalent in races with a woman candidate, but obviously not so in races with two men candidates.

\begin{tabular}{|c|c|c|c|c|}
\hline & Issue Coverage & $\begin{array}{c}\text { Feminine Policy } \\
\text { Scale }\end{array}$ & $\begin{array}{c}\text { Masculine Policy } \\
\text { Scale }\end{array}$ & Issue Coverage \\
\hline Mixed-gender & $\begin{array}{c}-0.0976^{* *} \\
(0.028) \\
\end{array}$ & & & \\
\hline $\begin{array}{c}\text { Man w/Woman } \\
\text { Opponent }\end{array}$ & 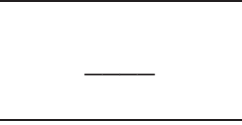 & $\begin{array}{c}-0.2801 * * \\
(0.051) \\
\end{array}$ & $\begin{array}{c}-0.0908 \dagger \\
(0.051) \\
\end{array}$ & $\begin{array}{c}-0.1099 * * \\
(0.035) \\
\end{array}$ \\
\hline Democrat & $\begin{array}{l}0.0319 \\
(0.028) \\
\end{array}$ & $\begin{array}{c}-0.0883^{\dagger} \\
(0.053) \\
\end{array}$ & $\begin{array}{c}-0.0601 \\
(0.049)\end{array}$ & $\begin{array}{l}0.0345 \\
(0.035)\end{array}$ \\
\hline Pre-2008 & $\begin{array}{l}0.0086 \\
(0.028) \\
\end{array}$ & $\begin{array}{l}0.0481 \\
(0.051) \\
\end{array}$ & $\begin{array}{l}0.0104 \\
(0.049) \\
\end{array}$ & $\begin{array}{c}-0.0122 \\
(0.033) \\
\end{array}$ \\
\hline Constant & $\begin{array}{c}0.3377^{* *} \\
(0.028)\end{array}$ & $\begin{array}{c}0.5931 * * \\
(0.049)\end{array}$ & $\begin{array}{c}0.4810^{* *} \\
(0.042)\end{array}$ & $\begin{array}{c}0.3456^{* *} \\
(0.031)\end{array}$ \\
\hline
\end{tabular}

Table 2. Policy and Trait Coverage of mixed-gender contests and men candidates with women opponents-Table shows OLS regression coefficients with standard errors in parentheses. ${ }^{\dagger} \mathrm{p}<0.1 \quad * \mathrm{p}<0.05 \quad * *_{\mathrm{p}}<0.01$ 
The analyses so far have evaluated simply if women candidates are covered differently from men candidates, regardless of whether the men candidates were running against a woman or another man. However, it is possible that men facing women opponents may be covered differently than those facing men opponents. To test if this is the case, I examine my fourth hypothesis, that mixed-gender campaigns will be covered differently than campaigns where two men are running against each other. I run analyses similar to those above, but with a different gender-related dummy variable. This variable is coded as 1 if the race is mixed gender, and 0 if both candidates are men. The results in Figure 3 are similar to those evaluating women versus men candidates' coverage. Abortion, education, and health care all have gender coefficients that are negative and statistically significant ( $\mathrm{p}<0.01)$, which indicates that candidates in mixed-gender races receive less coverage of these issues than candidates in men-only races. For masculine issues, coverage of the deficit reaches statistical significance $(p<0.01)$ with a negative coefficient. None of the other policy variables reach statistical significance in this model, indicating that, for masculine policy issues, candidates in mixed-gender races are only disadvantaged on issue coverage of the deficit.

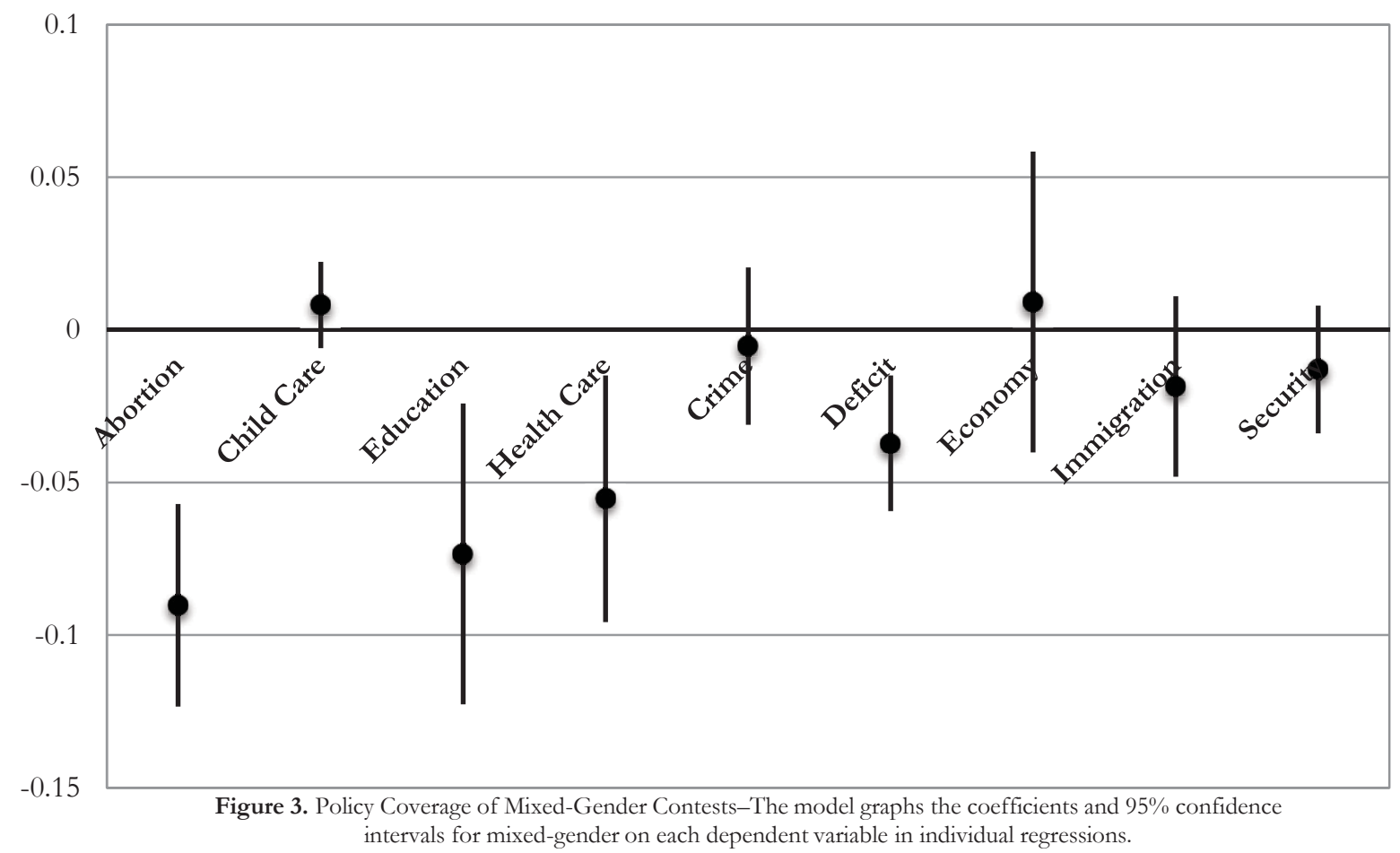

In an attempt to delineate whether the differences in coverage of mixed-gender races are due to coverage specifically of the men or women candidates, I examine gender in a third context: I limit my analysis to only the men candidates, and test how men running against women are covered differently from men running against men. Table $\mathbf{5}$ shows the results of the regression analysis of the masculine and feminine policy scale variables. In this case, the gender coefficient for both dependent variables is negative and statistically significant $(\mathrm{p}<0.1$ and $\mathrm{p}<0.001$ respectively), which indicates that men running against women are less likely than men running against men to receive coverage on both masculine and feminine policy issues.

Figure 4 shows the results from individual regressions with each specific policy issue as the dependent variables and with opponent gender as the independent variable. This analysis comes out with statistically significant coefficients for five of the nine policy issues. Significantly, all of these coefficients are negative, indicating that men running against women are overall less likely to receive issue coverage than men running against men. To confirm this result, I run a final regression analysis for the effect of opponent gender on issue versus horse race coverage, the results of which are in Table 6.

As expected, the coefficient for opponent gender is negative and statistically significant $(\mathrm{p}<0.01)$, supporting my assertion that men running against women receive significantly less issue coverage than men running against men. This final measure also supports my hypothesis that mixed-gender campaigns are covered differently from men-only races. 


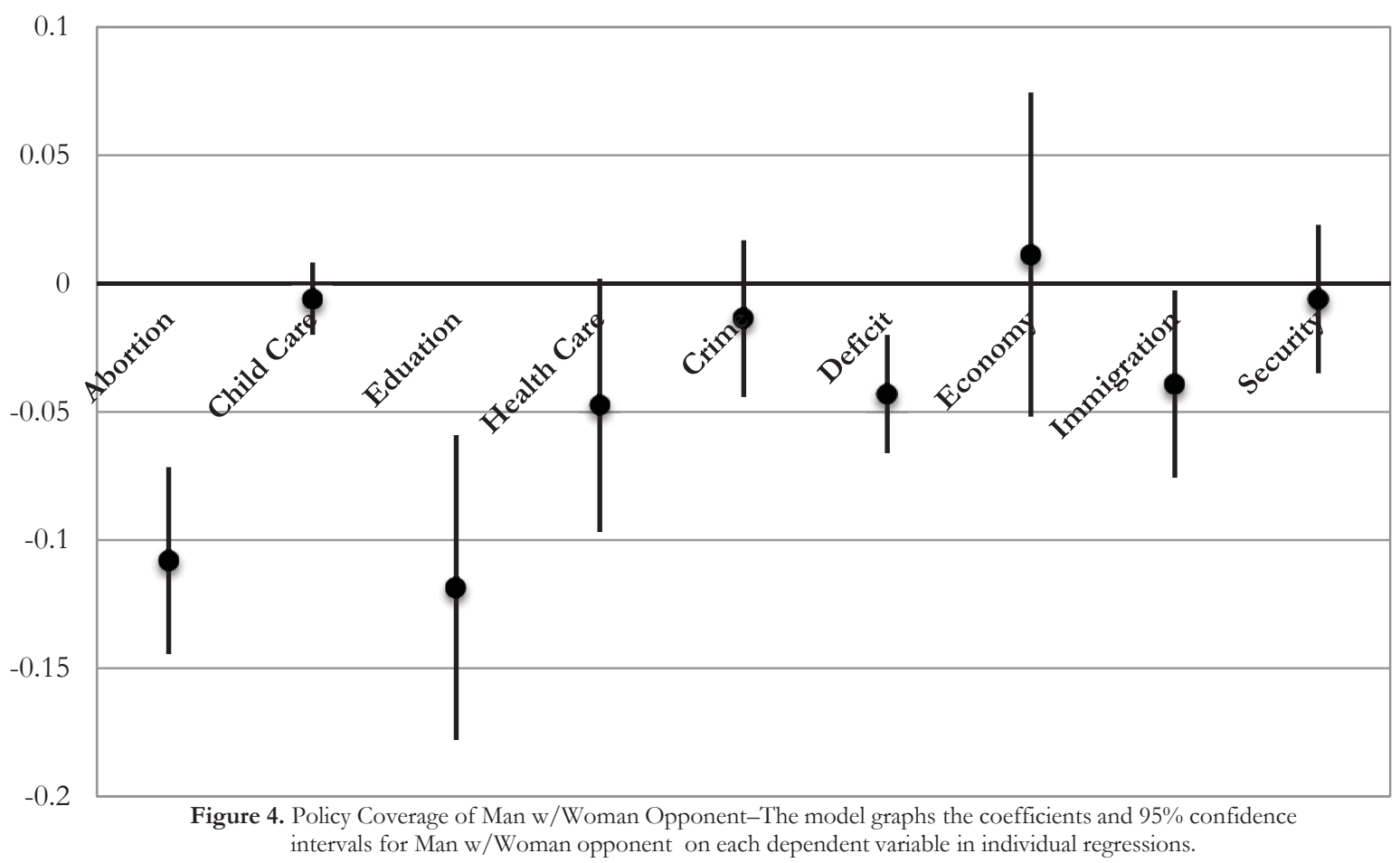

\section{DISCUSSION}

The findings of this paper clearly indicate that differences in media coverage exist depending on the gender of the candidates in gubernatorial elections. Although my findings provide mixed support for my first hypothesis, there is evidence of significant differences in newspaper coverage of men and women candidates. In terms of issue coverage, women candidates are more likely than men candidates to receive coverage on the issue of child care, but less likely to receive coverage on abortion, health care, and security issues. This is especially significant because several of the issues on which women receive less coverage are those where previous research suggests they would be advantaged by gender stereotypes. ${ }^{12,13,15,16}$ This suggests that gender stereotypes do not lead to increased coverage of the relevant issues in the newspaper coverage of gubernatorial campaigns. On the other hand, the difference might be a manifestation of Dittmar's finding that "male candidates, especially Democrats for whom women are a base of support, utilize gender-based messages and messengers to compensate for women's perceived natural advantage with female voters in mixed-gender contests". 35 This quotation suggests that the media's focus on some stereotypes over others may be a response the candidates' messaging rather than simple stereotyping. However, this explanation does not align with my findings that men running against women receive significantly less issue coverage on traditionally feminine issues than men running against men, unless men candidates in mixed-gender races discuss issues less. Finally, the reasons behind stereotyped coverage neither increase nor decrease the effects of gendered frames.

When it comes to adjectives used to describe candidates, I find evidence that the words used by journalists align with gender stereotypes. With women candidates especially likely to be described as able to "change government," and men candidates described as "experienced," campaign coverage reinforces gender stereotypes. While being able to "change government" can be considered a good quality, especially in anti-incumbent elections, the priming of gender overall seems likely to hurt rather than help women candidates for executive offices. ${ }^{18,36}$ Additionally, Dolan and Lynch, in a recent study of gender stereotypes in a range of electoral contexts, find that only a limited number of stereotyped traits are used by voters. ${ }^{16}$ Interestingly, while they measure all of the same stereotypes as this study, the ones that emerge in as significant in their study are those of women as more compassionate and men as more decisive ${ }^{16}$ - a different set of traits than those that emerged in this study. This difference might be explained by temporal changes reflected in the analysis, as their data focuses on a single election cycle (2010) rather than campaigns spread out over several years. Finally, while this study focuses on newspaper coverage, Dolan and Lynch's research surveys voters directly. The variability between the results might therefore stem from differences in how newspapers and voters treat stereotypes, or an effect of some confounding variables that were unaccounted for. 
Another aspect of newspaper coverage which can significantly influence voters, and thereby candidates' success, is issue coverage. ${ }^{20,21}$ While the differences I find in levels of issue coverage for women candidates fall just short of statistical significance, my analysis of mixed-gender versus all-men races indicates that there are differences that go beyond women candidates. These findings demonstrate that the effects of having a woman run for governor are not limited to the woman's campaign. Instead, the races overall receive less issue coverage than a race with two men candidates. If this trend is a product of the novelty factor that still seems to be associated with women gubernatorial candidates, the levels of issue coverage is likely to rebound to the same level as that of the races with two men running. However, if the trend continues as the novelty of women gubernatorial candidates wears off, this could mean an overall lower standard for coverage of policy positions in the future, if more women run for office.

Having candidates receive less issue coverage can potentially influence voter information levels about the candidates, ${ }^{26}$ and thereby cause voters to rely more heavily on gender cues. ${ }^{37}$ One explanation for the differences in levels of issue coverage might be that newspapers are more likely to cover an election with a woman candidate by focusing on gender and the potential for electing a woman governor for the first time. This frame seems to lead to more focus on the candidate's viability, and thereby more horse race coverage. However, as long as both the man and woman in the same race receive similar amounts of issue coverage, as the data suggests, the detrimental effects of the gender frame would be limited to those associated with priming gender prior to an election for an executive office..$^{18,36}$

The impact of a woman candidate on the campaign coverage is, surprisingly, the most obvious when comparing the coverage of men candidates with women opponents to men candidates with men opponents. The levels of issue coverage for men in mixedgender races are significantly lower than the corresponding levels for men in men-only contests. This difference is highlighted as nearly half of the dependent policy variables from masculine and feminine policy areas alike indicate that men running against women receive less coverage on those policy issues than their colleagues with men opponents. The lower levels of issue coverage might be explained by the media's tendency to cover mixed-gender races in terms of gendered frames, as discussed above.

This finding is perhaps the most interesting, as mixed-gender races are likely to become more common over time. However, as mixed-gender races become more common, and the novelty of having a woman run for governor wears off, we might see more similar news coverage between different types of contests. ${ }^{8}$ Additionally, Eagly and Karau assert that "to the extent that leader roles become more androgynous, the tendency to perceive women as less qualified than men should lessen" (578). ${ }^{19}$ This is another factor that could influence future campaign coverage, as a change in perception where leadership roles are seen as more androgynous could cause gender priming to be less powerful in candidate coverage and evaluations. However, considering that women's levels of representation across levels of office are increasing at low rates, and that women represent less than 30 percent of elected officials at all levels of office, ${ }^{3}$ this move towards more androgynous perceptions of leadership roles seems unlikely to happen any time soon.

Overall, the data shows limited evidence of gender stereotypes being used in newspaper coverage of gubernatorial campaigns, while most variables fail to reach statistical significance. The implications of these findings are that, while some gender stereotypes still influence aspects of gubernatorial campaigns, the assertions of recent studies, that the prevalence of gender stereotypes is in decline, ${ }^{8,16}$ seem plausible. With a decreasing emphasis on gender stereotypes, more women might pursue elected office, if the barrier of a perceived hostile media environment is reduced. ${ }^{5}$ As outlined earlier, electing more women to office could thereby improve women's descriptive as well as substantive representation.

To further address gendered differences in news coverage, future research should focus on how races with men running against women differ from races with two women candidates. One problem with this line of research is the limited amount of data available, since these contests are still fairly rare, especially at the statewide level. Media coverage from outlets other than newspapers might also provide different frames for mixed-gender races. The perpetuation of gender stereotypes through cable news, social media, and political blogs are all potential areas that could complement this study. This aspect requires further research, especially considering the expanding knowledge gap and difference in information sources between the most and least informed voters. ${ }^{38}$ Finally, as more women are successful in their bids for state executive positions, new possibilities emerge with regards to studying the role of incumbency for women governors, as well as changes in the media frames, as the novelty of women candidates for executive positions wears off.

\section{ACKNOWLEDGMENTS}

I am thankful to the Politics department at Sewanee: The University of the South and the Dugan Education and Research Grant for support throughout the research process, the anonymous reviewers for their feedback, and Drs. Melody Crowder-Meyer and JoyAnna Hopper for their guidance and help from start to finish. 


\section{REFERENCES}

1. Mayo, N. (2008) Perdue Pledges Not to Forget Small Counties. Sun Journal.

2. Williams, J., Dempsey, R. (2014) What works for women at work: four patterns working women need to know, NYU Press, New York.

3. CAWP. Women in Elective Office 2018. bttp:// wnw.canp.rutgers.edu/women-elective-office-2018 (accessed February 4th, 2018).

4. CAWP. History of Women Governors. http:/ / wnww.cawp.rutgers.edu/ history-women-governors (accessed February 9 th, 2018).

5. Fox, R. L., Lawless, J. L. (2014) Uncovering the Origins of the Gender Gap in Political Ambition. American Political Science Review 108(3), 499-519.

6. Atkeson, L. R. (2003) Not All Cues Are Created Equal: The Conditional Impact of Female Candidates on Political Engagement The Journal of Politics 65(4), 1040-1061.

7. Swers, M. L. (2013) Women in the Club: gender and policy making in the senate. The University of Chicago Press, Chicago.

8. Hayes, D., Lawless, J. L. (2016) Women on the Run: Gender, Media, and Political Campaigns in a Polarized Era. Cambridge University Press, New York.

9. Fridkin, K., Kenney, P. (2013) The Changing Face of Representation: The Gender of U.S. Senators and Constituent Communications, University of Michigan Press, Ann Arbor, MI.

10. Dolan, K. (2014) Attitudes, Stereotypes, and Support for Women Candidates, in When Does Gender Matter? 49-90. Oxford University Press, New York.

11. Volden, C., Wiseman, A. E. (2014) The Habits of Highly Effective Lawmakers, in The Lawmakers: Legislative Effectiveness in the United States Congress, Cambridge University Press, New York.

12. Banwart, M. (2010.) Gender and Candidate Communication: Effects of Stereotypes in the 2008 Election. American Behavioral Scientist 54(3), 265-283.

13. Huddy, L., Terkildsen, N. (1993) Gender stereotypes and the perception of male and female candidates. American Journal of Political Science 37(1), 119-147.

14. Benoit, W., Hansen, G. (2004) Issue ownership in primary and general presidential debates. Argumentation and Advocacy 40(3),143-153.

15. Kahn, K. (1994) Does Gender Make a Difference? An Experimental Examination of Sex Stereotypes and Press Patterns in Statewide Campaigns. American Journal of Political Science 38(1), 162-195.

16. Dolan, K., Lynch, T. (2016) The Impact of Gender Stereotypes on Voting for Women Candidates by Level and Type of Office, in Politics \& Gender 12, 573-595.

17. Dolan, K. (1997) Gender Differences in Support for Women Candidates. Women \& Politics 17(2), 27-4.

18. Fox, R. L., Oxley, Z. M. (2003) Gender stereotyping in state executive elections: Candidate selection and success. Journal of Politics 65(3), 833-850.

19. Eagly, A. H., Karau, S. (2002) Role congruity theory of prejudice toward female leaders. Psychological Review 109(3), 573-598.

20. Druckman, J. N., Parkin M. (2005) The Impact of Media Bias: How Editorial Slant Affects Voters. Journal of Politics 67(4), 1030-1049.

21. Hayes, D. (2008) Does the Messenger Matter? Candidate-Media Convergence and Its Effects on Voter Issue Salience. Political Research Quarterly 61(1), 134-146.

22. Shor, E., Rijt, A., Ward, C., Askar, S., Skiena, S. (2014) Is There a Political Bias? A Computational Analysis of Female Subjects' Coverage in Liberal and Conservative Newspapers. Social Science Quarterly 95(5) 1213-1229.

23. Dolan, K., Deckman, M., Swers, M. (2011) Women as Candidates for Elective Office, in Women and Politics 128-171, Pearson, New York.

24. Fowler, L., Lawless, J. L. (2009) Looking for Sex in All the Wrong Places: Press Coverage and the Electoral Fortunes of Gubernatorial Candidates. Perspectives on Politics 7(3), 519-536.

25. Herrnson, P. S., Lay, C., Stokes, A. K. (2003) Women Running 'as Women': Candidate Gender, Campaign Issues, and VoterTargeting Strategies. The Journal of Politics 65(1), 244-255.

26. Druckman, J. N. (2004) Priming the Vote: Campaign Effects in a U.S. Senate Election. Political Psychology 25(4), 577-594.

27. Koenig, A. M., Eagly, A. H., Mitchell, A. A., Ristikari, T. (2011) Are leader stereotypes masculine? A meta-analysis of three research paradigms. Psychological Bulletin 137(4), 616-642.

28. Niven, D. (2012) An Interesting Bias: Lessons from an Academic's Year as a Reporter. Political Science and Politics, 45(2), 259264.

29. Goldenberg, E., Kahn, K. F. (1991) The Media: Obstacle or Ally of Feminists? Annals of the American Academy of Political and Social Science 515, 104-113.

30. Brians, C. L., Wattenberg, M. P. (1996) Campaign Issue Knowledge and Salience: Comparing Reception from TV Commercials, TV News and Newspapers. American Journal of Political Science 40(1), 172-193.

31. D'Alessio, D., Allen, M. (2000) Media bias in presidential elections: a meta-analysis. Journal of Communication 50(4), 133-156.

32. Gidengil, E., Everitt, J. (2003) Talking Tough: Gender and Reported Speech in Campaign News Coverage. Political Communication 20, 209-232. 
33. Arnold, D. R. (2004) Effects of Newspaper Coverage on Citizens, in Congress, the Press, and Political Accountability, 221-243, Princeton University Press, Princeton.

34. Holman, M. R., Merolla, J. L., Zechmeister, E. J. (2016) Terrorist Threat, Male Stereotypes, and Candidate Evaluations. Political Research Quarterly 69(1), 134-147.

35. Dittmar, K. (2015) Navigating Gendered Terrain: Stereotypes and Strategy in Political Campaigns. Temple University Press, Philadelphia.

36. Cassino, D. (2016) Gender Is Costing Hillary Clinton Big among Men. US APP. bttp:// eprints.lse.ac.uk/65949/1/blogs.lse.ac.uk (accessed November 19, 2016).

37. McDermott, M. L. (1998) Race and Gender Cues in Low-Information Elections. Political Research Quarterly 51(4), 895-918.

38. Prior, M. (2005) News vs. Entertainment: How Increasing Media Choice Widens Gaps in Political Knowledge and Turnout. American Journal of Political Science 49, 577-592.

\section{ABOUT THE STUDENT AUTHOR}

Karen Bjerre graduated from Sewanee: The University of the South in 2017, with a Bachelor of Arts in politics. This project was presented as her honors thesis. She currently attends Copenhagen University, Denmark, where she is working towards her MSc in political science.

\section{PRESS SUMMARY}

I explore print media coverage of 20 different gubernatorial races between 2004 and 2014 to discover how the presence of a woman candidate in a political campaign affects its media coverage. I find that races with a woman candidate have fewer news stories that cover policy issues than races with two men candidates. I also find differences in how men and women candidates are described in the media: women candidates are more likely to be described as able to "change government," while men candidates are more likely to be described as "experienced." Previous research suggests that voters favor traditionally masculine traits over traditionally feminine traits when evaluating candidates for public office, which means that the difference in media coverage may therefore influence women candidates' chances of getting elected, and thereby women's role in government.

\section{APPENDIX}

\section{Table 1}

\begin{tabular}{|c|c|c|c|c|c|c|}
\hline Contest Pair & Name & Party & Gender & Year & State & \% Vote \\
\hline AK/MT-0 & Sarah Palin & Republican & $\mathrm{F}$ & 2006 & $\mathrm{AK}$ & 48.33 \\
\hline $\mathrm{AK} / \mathrm{MT}-0$ & Tony Knowles & Democrat & $\mathrm{M}$ & 2006 & $\mathrm{AK}$ & 40.97 \\
\hline AK/MT-0 & Brian Schweitzer & Democrat & M & 2004 & MT & 50.44 \\
\hline $\mathrm{AK} / \mathrm{MT}-0$ & Bob Brown & Republican & $\mathrm{M}$ & 2004 & MT & 46.02 \\
\hline FL/VA-1 & Rick Scott & Republican & $\mathrm{M}$ & 2010 & FL & 48.9 \\
\hline FL/VA-1 & Alex Sink & Democrat & $\mathrm{F}$ & 2010 & FL & 47.7 \\
\hline FL/VA-1 & Terry McAuliffe & Democrat & $\mathrm{M}$ & 2013 & $\mathrm{VA}$ & 47.75 \\
\hline FL/VA-1 & Ken Cuccinelli & Republican & $\mathrm{M}$ & 2013 & $\mathrm{VA}$ & 45.23 \\
\hline MA/VT-1 & Peter Shumlin & Democrat & $\mathrm{M}$ & 2010 & VT & 49.5 \\
\hline MA/VT-1 & Brian Dubie & Republican & $\mathrm{M}$ & 2010 & $\mathrm{VT}$ & 47.7 \\
\hline MA/VT-1 & Charlie Baker & Republican & $\mathrm{M}$ & 2014 & MA & 48.4 \\
\hline MA/VT-1 & Martha Coakley & Democrat & $\mathrm{F}$ & 2014 & MA & 46.5 \\
\hline MO/ID-0 & Butch Otter & Republican & $\mathrm{M}$ & 2006 & ID & 52.67 \\
\hline $\mathrm{MO} / \mathrm{ID}-0$ & Jerry Brady & Democrat & M & 2006 & ID & 44.11 \\
\hline MO/ID-0 & Matt Blunt & Republican & $\mathrm{M}$ & 2004 & $\mathrm{MO}$ & 50.83 \\
\hline MO/ID-0 & Claire McCaskill & Democrat & $\mathrm{F}$ & 2004 & $\mathrm{MO}$ & 47.85 \\
\hline NC/FL-0 & Charlie Crist & Republican & $\mathrm{M}$ & 2006 & FL & 52.2 \\
\hline NC/FL-0 & Jim Davis & Democrat & $\mathrm{M}$ & 2006 & FL & 45.1 \\
\hline NC/FL-0 & Beverly Perdue & Democrat & $\mathrm{F}$ & 2008 & $\mathrm{NC}$ & 50.27 \\
\hline NC/FL-0 & Pat McCrory & Republican & $\mathrm{M}$ & 2008 & $\mathrm{NC}$ & 46.88 \\
\hline NM/OR-1 & Susana Martinez & Republican & $\mathrm{F}$ & 2010 & NM & 53.29 \\
\hline
\end{tabular}




\begin{tabular}{|c|c|c|c|c|c|c|}
\hline NM/OR-1 & Diane Denish & Democrat & $\mathrm{F}$ & 2010 & NM & 46.55 \\
\hline NM/OR-1 & John Kitzhaber & Democrat & M & 2010 & OR & 49.29 \\
\hline NM/OR-1 & Chris Dudley & Republican & M & 2010 & OR & 47.77 \\
\hline NV/IA-0 & Chet Culver & Democrat & M & 2006 & IA & 54.02 \\
\hline NV/IA-0 & Jim Nussle & Republican & M & 2006 & IA & 44.38 \\
\hline NV/IA-0 & Jim Gibbons & Republican & M & 2006 & $\mathrm{NV}$ & 47.93 \\
\hline NV/IA-0 & Dina Titus & Democrat & $\mathrm{F}$ & 2006 & NV & 43.92 \\
\hline RI/MD-1 & Larry Hogan & Republican & M & 2014 & $\mathrm{MD}$ & 51 \\
\hline RI/MD-1 & Anthony Brown & Democrat & M & 2014 & $\mathrm{MD}$ & 47.2 \\
\hline RI/MD-1 & Gina Raimondo & Democrat & $\mathrm{F}$ & 2014 & RI & 40.7 \\
\hline RI/MD-1 & Allan Fung & Republican & M & 2014 & RI & 36.2 \\
\hline SC/PA-1 & Tom Corbett & Republican & M & 2010 & $\mathrm{PA}$ & 54.49 \\
\hline SC/PA-1 & Dan Onorato & Democrat & M & 2010 & PA & 45.51 \\
\hline SC/PA-1 & Nikki Haley & Republican & $\mathrm{F}$ & 2010 & $\mathrm{SC}$ & 51.4 \\
\hline SC/PA-1 & Vincent Sheheen & Democrat & M & 2010 & SC & 47 \\
\hline WA/VA-0 & Tim Kaine & Democrat & $\mathrm{M}$ & 2005 & VA & 51.72 \\
\hline WA/VA-0 & Jerry Kilgore & Republican & M & 2005 & VA & 45.99 \\
\hline WA/VA-0 & Christine Gregoire & Democrat & $\mathrm{F}$ & 2004 & WA & 48.873 \\
\hline WA/VA-0 & Dino Rossi & Republican & $\mathrm{M}$ & 2004 & WA & 48.868 \\
\hline
\end{tabular}

Overview of coded variables

Basic Data: Days before election; Tone (positive, neutral, negative); Mentions candidate's gender; Horse race coverage; Issue story

Candidate's Appearance: Positive mention; Neutral mention; Negative mention

Policy Mentions (F): Abortion; Child care; Education; Health care

Policy Mentions (M): Crime; Deficit; Economy; Immigration; National security

Trait Mentions (F): Change government; Compassionate; Consensus building; Honest

Trait Mentions (M): Decisive; Experienced; Intelligent; Leadership

Voter Social Group: Gender; Other

\section{Inter-coder reliability}

Two undergraduate students each spent 10 hours to code 10 percent of the primary dataset in order to measure intercoder reliability. Krippendorff's alpha for each individual variable is noted, with the total number of mentions in the primary dataset noted in parentheses (out of 1152).

\begin{tabular}{|c|c|c|c|c|}
\hline $\begin{array}{l}\text { Candidate's gender } \\
0.662 \\
(44)\end{array}$ & $\begin{array}{l}\text { Education } \\
0.798 \\
(261)\end{array}$ & $\begin{array}{l}\text { Immigration } \\
0.891 \\
(83)\end{array}$ & $\begin{array}{l}\text { Honest } \\
0.487 \\
(30)\end{array}$ & $\begin{array}{l}\text { Social group: Gender } \\
0.602 \\
(34)\end{array}$ \\
\hline $\begin{array}{l}\text { Horse race story } \\
0.576 \\
(808)\end{array}$ & $\begin{array}{l}\text { Health care } \\
0.751 \\
(145)\end{array}$ & $\begin{array}{l}\text { National security } \\
0.628 \\
(46)\end{array}$ & $\begin{array}{l}\text { Decisive } \\
0 \\
(0)\end{array}$ & $\begin{array}{l}\text { Social group: } \\
\text { Other } \\
0.792 \\
(72)\end{array}$ \\
\hline $\begin{array}{l}\text { Issue story } \\
0.576 \\
(344)\end{array}$ & $\begin{array}{l}\text { Crime } \\
0.877 \\
(59)\end{array}$ & $\begin{array}{l}\text { Change government } \\
0.259 \\
(19)\end{array}$ & $\begin{array}{l}\text { Experienced } \\
0.168 \\
(52)\end{array}$ & \\
\hline $\begin{array}{l}\text { Abortion } \\
0.835 \\
(96)\end{array}$ & $\begin{array}{l}\text { Deficit } \\
0.446 \\
(39)\end{array}$ & $\begin{array}{l}\text { Compassionate } \\
1 \\
\text { (1) }\end{array}$ & $\begin{array}{l}\text { Intelligent } \\
1 \\
\text { (9) }\end{array}$ & \\
\hline Child care & Economy & Consensus building & Leadership & \\
\hline
\end{tabular}



0.190
0.727
0
0.557

As the table shows, several of the variables have very few mentions in the primary dataset, which helps explain the extreme alpha values. Additionally, some of the latent variables, especially those involving trait descriptions are more difficult to code consistently than specific policy mentions.

\section{CODEBOOK}

Basic data

Mentions candidate's gender - Does the article mention that the candidate is a woman (or man)? If so, it's a 1. if not, please put a 0. Examples of this would be "first female candidate" and similar statements. For this variable, it is important to note that there are both men and women candidates in the dataset (the 'gender' column will tell you which). Only code this variable a 1 if the gender reference is about that specific candidate. For example, an article that is a part of the Tony Knowles dataset would not be coded 1 is it mentions that Sarah Palin is a woman.

Horse race coverage - Every article will be classified as either horse race coverage or issue story. Horse race stories include articles detailing campaign events, stories about polls, debate times, and similar stories.

Issue story - This is the opposite of a horse race story. These will generally detail specific policy positions/issues facing the state. Remember that one of these (horse race) columns will be a 1 and the other a 0 for every article.

Policies

Note that articles do not have to be *about* the issue to be coded as mentioning them.

Abortion - Does the article mention abortion? If so, it is a 1. If not, it is a 0 . Mentions of being "pro-life/choice" also qualify.

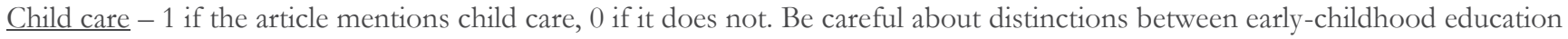
(not child care) and child care.

Education -1 if the article mentions education, 0 if it does not. Be aware that mentions of 'education' in a person's title, for example "board of education," "education supervisor," etc., do not qualify as mentions of education.

Health care -1 if the article mentions health care, 0 if it does not.

Crime -1 if the article mentions crime, 0 if it does not.

Deficit -1 if the article mentions the deficit, 0 if it does not. This variable is about the budget deficit, so be aware that for example deficits in polls do not qualify.

Economy - 1 if the article mentions the economy, 0 if it does not. Variations such as "the economic downturn" and the like also count.

$\underline{\text { Immigration }}-1$ if the article mentions immigration, 0 if it does not.

National security -1 if the article mentions national security, 0 if it does not. These will typically prop up as discussions about the Iraq war/terror threat.

Traits

Note that the trait mentions do not have to reference the specific candidate. References to their opponents/other politicians also count. Also, the negative versions of adjective (dishonest, inexperienced, etc) also count.

Change government - If the article mentions someone "changing the way the government works," it's a 1. If not, it's a 0. This one can have some more variations, but use your best judgment.

Compassion - If the article mentions someone being compassionate, it is a 1 . If not, it is a 0 .

Consensus building - If the article mentions someone being consensus building, it is a 1 . If not, it is a 0 .

Honest - If the article mentions someone being honest, it is a 1 . If not, it is a 0 .

Decisive - If the article mentions someone being decisive, it is a 1 . If not, it is a 0 .

Experienced - If the article mentions someone being experienced, it is a 1 . If not, it is a 0 .

Intelligent - If the article mentions someone being intelligent, it is a 1 . If not, it is a 0.

Leadership - If the article mentions someone's leadership qualities, it is a 1. If not, it is a 0 . There might be some variation along the lines of "strong leader," and such, which counts. On the other hand, mentions of the congressional leadership and the like do not count.

Voter social group

Gender - If the article mentions something about women voters (“the woman vote," "doing well with women"), it's a 1. If not, it's a 0 .

Other - If the article mentions specific demographic voter groups other than gender (race, religion, etc.), it's a 1 . If not, it's a 0. 